\title{
Bernard Shaw y los médicos
}

El Dilema del doctor.-En esta obra teatral de Bernard Shaw, como en muchas de las suyas, lo mejor es el prefacio. De fal manera Bernard Shaw lo pone todo en el prefacio. que la obra teatral, una vez leído éste, casi no nos reserva ninguna sorpresa. No encontramos en ella sino la condensación de todas sus ideas fundamentales, sin el enmarañamiento encantador de disquisiciones, de audacias, de insolencias y de genialidades, con que el gran inglés nos introduce a las bambalinas originalisimas de su teatro.

-El dilema del doctor, no es una obra nueva en Inglaterra, pero si lo es para los lectores de español, idioma al que acaba de ser vertido. No creo que Bernard Shaw sea un escritor leido suficientemente. El premio Nobel acaba de enfocarlo con sus rayos amarillos de francos y de publicidad, y seguramente Bernard Shaw empieza a leerse mucho más. Es dificil decir si es conveniente o no que esto suceda; para ello habría que dilucidar primero si es conveniente o no arrancarnos las ilusiones que solemos llevar con nosotros aún los más desilusionados. De mí sé decir que cada libro de Bernard Shaw me las ha arrancado a puñados, y que el dolor que me ha producido esta poda semi-salvaje, me ha hecho percatarme de que yo, que no creía poseer ninguna de tan exóticas plantas, tenia una verdadera maleza de ellas dentro del corazón.

Geneneralmente cuando se lee a Bernard Shaw. se le acusa de alrabiliario y el lector se pone de punta con él. Yo tengo que confesar que me ha sucedido otro lanto. Mientras me engolfaba en el nutridisimo prefacio de su Santa Juana, abo- 
rrecia sus palabras fascinadoras, y la cruda luz que arroja so. bre la más asombrosa heroina católica. luz cruda y amorosa. pero demasiado radiante, para no amenguar y lastimar su piel dos veces delicada de mujer y de sanía.

El fanatismo en general, es una ilusión atroz, pero no por ello es menos una ilusión, y. Bernard Shaw parece dispuesto a emprenderla con todas las ilusiones que restan en la humanidad. En este último libro, las emprende contra el gran fanalismo de la medicina, que. con la religión, son los más grandes, úliles y verdaderos fanatismos que le quedan a este pobre ser civilizado que es el hombre de hoy: por cuanto el primero es la esperanza. la fuerte esperanza que hace caminar al hombre entre todo el género de muertes diversas con que le amenaza la enfermedad, con la seguridad de vencerlas, y el segundo es la seguridad de que, una vez muerto, no estará muerto de verdad sino aparentemente, porque su espiritu se irá a vivir en otras partes una vida mejor o peor, pero en fin, una vida, que resultará siempre mucho menos espantosa que la muerte definitiva.

$\mathrm{Y}$ cuando mal que mal ibamos tirando con todas estas ilusiones, los creyentes seguros de la vida eterna luera de este mundo, y los no creyentes, seguros de una vida susceptible de zurcirse y volverse a zurcir gracias a los crecientes progresos de esa maga blanca que se llama la medicina y de ese mago de cualquier color que se Ilama el doctor, Bernard Shaw nos dice con su acento impasible de buen inglés:

-Tralad a las personas que dicen que pueden curar las enfermedades, como a los que dicen la buena ventura.

No os empeñéis en vivir eternamente, pues no lo lograréis.

$\mathrm{Y}$ acaso como un consuelo:

-Usad vuestra salud aun hasta el punto de desgastarla. Para eso la tenéis. Gastad toda la que tengáis antes de morir, y no sobreviváis a vosotros mismos».

Lo peor en este libro es que Bernard Shaw no es enemigo de los médicos! Ojalá lo luese! Siempre se desconfia de las opiniones de los enemigos, por honrados que sean, porque la enemistad se parece mucho al odio y el odio es una pasión 
violenta. Todo lo conirario. Bernard Shaw parece amar a los médicos, o a lo menos tenerles buena voluntad. Todo su libro es una excusa para ellos. Absolutamente de nada les echa la culpa. Es a las gentes en general y a los clientes de los médicos en particular, a quienes Bernard Shaw lanza su eYo acuso, con una saña y una lógica implacable. Dice:

- Cuando más tremenda es la mutilación. más cobra el mutilador. El que arregla una uña encarnada del dedo gordo del pie, cobra unos pocos chelines; el que practica una operación en las visceras, recibe centenares de guineas.... y luego: .Voces escandalizadas murmuran que esas operaciones son necesarias. puede que lo sean. También puede que sea necesario ahorcar algunos hombres y derribar algunas casas. Pero tenemoś buen cuidado en esos casos de no consultar al verdugo y a los que manejan la piqueta. Si obráramos de modo distinto, no estaria seguro el pescuezo de nadie ni la casa de nadie quedaría en pie. .

Según Bernard Shaw, el hecho de que los médicos reciban dinero por las enfermedades de sus clientes y no por la salud que puedan proporcionar a estos mismos, es el principal culpable de los yerros y deficiencias de esta profesión.

Sólo hay un punto en el que Shaw se muestra francamente enemigo de los médicos, un punto en que es imposible dejar de estar con él, y es en lo que toca a la vivisección. Y así dice: No conozco a ninguna persona reflexiva y bien informada que no esté persuadida de que la tragedia de la enfermedad hoy dia nos entrega sin defensa a las manos de una profesión de la que desconfiamos profundamente, porque no solamente defiende y ejerce las más atroces crueldades en la consecución de conocimientos y las justifica con fundamentos que lo mismo justificarian el que practicáramos en nosotros mismos o nuestros hijos, o destruyendo a Londres por un incendio para ensayar un extintor patentados.

Y siempre a propósito de los médicos, Bernard Shaw nos dice una cosa muy sencilla en la que no queriamos pensar. por el instintivo afán de resguardar nuestras esperanzas, y es la si- 
guiente: Hay ofra dificultad para fiarse en el honor y la conciencia de un médico. Los médicos son exactamente como los demás hombres: la mayor parte no tiene ni honor ni conciencia....

Por lo mismo. Bernard Shaw no exige de los médicos nada, y los defiende con todo género de razonamientos de peso en lo que respecta a los errores de su profesión. Cuando un médico es acusado por inhabilidad profesional. Bernard Shaw se indigna. Dice: Se ha infundido al abogado. al juez y al jurado. la idea de creer que todo médico puede, con una mirada a la lengua del paciente. un toque al pulso y otra mirada al termómetro, diagnosticar con absoluta seguridad el estado patológico de dicho paciente, así como disecando un cadáver puede poner. sin equivocarse, el dedo en la causa de la muerte. Dero foda esa supuesta infalibilidad es imaginaria y tratar a un médico como si sus equivocaciones fuesen necesariamente maliciosas e interesadas (deducción inevitable de la premisa de que el médico siendo omniciente, no puede equivocarse) seria tan injusto como vilipendiar al boticario más próximo por no estar surtido para poder suministrarnos por seis peniques, de un frasco de elixir de larga vida. o al dueño del garage vecino. por no vender el movimiento continuo en bidones de a litro. .

Una de las cosas que le llaman la atención a Bernard Shaw. y a cualquier lector, una vez que Bernard Shaw se las ha hecho ver, es la circunstancia de que mantenga la fe en los médicos, a pesar de la absoluta falta de exactilud en su ciencia, hecho comprobado por la eterna discrepancia de los médicos entre si respecto a cualquier género de enfermedades, y así dice: epues hay quien prescribe seis o siete venenos de la farmacopea para una fiebre tan vulgar como es la producida por una enteritis, mientras otro no tolera medicamento alguno: uno pone a dieta rigurosa al paciente, otro le sobrealimenta; uno considera urgente la operación que otro califica de innecesaria y peligrosa; uno recomienda alcohol y carne y otro prohibe terminantemente ambas cosas. Todas estas discrepancias no se producen entre buenos y malos médicos como podría creerse, sino 
entre facultativos de idéntica capacidad y renombre... Hasta el hecho de que los mismos médicos mueren de las mismisimas enfermedades cuya curación es su especialidad, pasa sin ser notado. Nos guardamos de decir con sorna: salvan a otros y no pueden salvarse a si mismos. No. Su repulación queda incólume. cimentada como el palacio de un rey africano sobre un montón de cadáveres, y el resultado es que el fallo es contrario al reo demandado cuando éste es un médico acusado de haber contribuido con malas intenciones a la muerte de alguien. Afortunadamente para los médicos, se encuentran muy pocas veces en tal situación, porque es muy difícil probar algo contra ellos. La única prueba que puede decidir en una causa por homicidio médico, es la de los peritos, es decir, el informe de of́ros médicos, y no hay médico que no deje a un compañero diezmar a toda una región, antes que violar los lazos de la profesión informando contra él. .

A pesar de que Bernard Shaw cree a pie juntillas en la fraternidad profesional de los médicos, hay un punto en el que reconoce un desacuerdo absoluto y es el que respecta a la cuestión de los precios. Observa a este respecto que cel que lleva dos guineas por consulta. o sea dos libras esterlinas y cuatro chelines, nunca cree que acierta el que sólo cobra cinco chelines, pues si lo creyese, se le podria reprochar que lleva de más una libra y diecisiete chelines. Asi pues hasta el lego en la materia tiene que enterarse de que la infalibilidad no es completa, puesto que se paga a precios diferentes, y con los precios varía la calidad.

A pesar de lodas estas observaciones, en el magnifico libro de Bernard Shaw, no se advierte, como repetimos anteriormente mala voluntad alguna hacia los médicos. A lo sumo se le puede tachar de incredulidad, y lo peor del caso, de incredulidad contagiosa. Probablemente, el propio Shaw cree más en los médicos que lo que se deduce del prefacio y de la comedia a que ahora nos referimos, y no sería del todo extraño que, mientras cualquier lector sugestionable, una vez leido este libro, renuncie 
a consultar a los médicos para el resto de sus dias. Bernard Shaw no deje de llamar al suyo a la menor indisposición.

Sin embargo, hay otro punto aparte del que toca la vivisección, en que el recién agraciado por el premio Nobel, se demuestra absolutamente irreductible, para cuya lucha no deja de poner en juego todas las razones que sugiere su observación y su inteligencia: la inoculación.

Su comedia sugiere el caso de un joven enfermo de tuberculosis a quien se pretende salvar por medio de la tuberculina de Koch. Esto ocurre en un centro de eminentes médicos ingleses. Sin embargo, el enfermo que posiblemente tenía vida para un año, muere en quince dias. No porque la tuberculina de Koch sea más que ineficaz, una arma terrible, sino porque fué aplicada en un mal momento. Leamos lo que a este propósito dice Bernard Shaw: -Los descubrimientos de Sir Almroth Wright han demostrado que los sorprendentes resultados que hicieron en 1894 desistir de aplicar la tuberculina de Koch, no fueron accidentales, sino fenómenos perfeclamente normales e inevitables causados por la infección de vacunas peligrosamente fuertes en un momento impropio y que aumentaron la dolencia en vez de estimular la resistencia del enfermo. Para acertar el momento propio, son necesarios un laboratorio y un cuerpo de técnicos inteligentes. El médico práctico corriente, no teniendo la experiencia necesaria ni disponiendo de un laboratorio. siempre se fia al azar, y si el resultado es desgraciado, dice que no es debido a la inoculación, sino a alguna otra causa, invocándose con frecuencia, sin mucho tacto, el alcoholismo o la vida disoluta del enfermo..., Y luego: eno hay la más mínima probabilidad de que el lado económico del asunto se modifique. Nunca se les ha advertido de que la práctica de cualquier método de extirpar una enfermedad no depende solamente de su eficacia. Sino también de su coste. Por ejemplo, precisamente en estos momentos, el mundo se vuelve loco con las maravillas del radio que excitan nuestra credulidad como los milagros de Lourdes excitan la de los calólico-romanos. Supongamos que fuese un hecho el que todo niño en el mundo pudiese ser absoluta- 
mente inmunizado contra todas las enfermedades durante toda su vida fomando media onza de radio por cada cuartilla de leche. El mundo no por eso ganaria en salud. porque ni aun un príncipe heredero, ni aun el hijo de un rey de la carne de Chicago, podria sostener los gastos del tratamiento. No obstante, es dudoso el si los médicos por tal razón se abstendrian de recelarlo.

No se limila sólo Bernard Shaw a indicar una por una las graves fallas existentes en la profesión médica, sino que no trepida en hacer las indicaciones que, según su manera de pensar. vendrian a subsanar, si no todos, gran parte de los susodichos errores. Un médico de los médicos, el sistema que considera más eficaz contra tan grandes daños, es el de convertir al médico privado en el médico público:

-Ya tenemos con el delegado médico de Sanidad, una clase de médico que está libre de las peores penalidades, y por lo tanto de los peores vicios del médico práctico particular. Su siluación depende. no del número de personas que eslán enfermas, sino del número de personas que están buenas. Se le aprecia, como debiera ser para todos los médicos y tratamientos, por las estadísticas vitales de su distrito. Cuando la cifra de las defunciones sube, su crédito baja. Como todo aumento de sueldo depende del resultado de un debate público sobre el estado sanitario del terrilorio a su cargo. tienen interés en que la morlalidad se reduzca al mínimum posible. Tiene una posición segura, digna, responsable, independiente, basada enteramente sobre la salud pública, mientras que el médico corriente. tiene una posición precaria, irresponsable, servil, basada enteramente en la prevalencia de las enfermedades.

Esto se pareceria al sistema chino, que según he oido decir, consiste en que cada familia pague un tanto al médico al mes o al año, cantidad que se deja de pagar inmedialamente por la familia cuyos miembros, uno o varios, caen enfermos. 